\title{
Avaliação da influência da adição de nutrientes no processo de autocicatrização de fissuras em materiais a base de cimento a partir do emprego da bactéria Bacillus subtilis (AP 91)
}

\author{
P. Ghellere ${ }^{1,2}$ *, S. Lenz ${ }^{1}$, M. R. Z. Passarini ${ }^{2}$, A. C. P. Dos Santos ${ }^{1}$; E. Possan ${ }^{1}$ \\ *Polyana Ghellere: p_ghellere@hotmail.com \\ ${ }^{1}$ Departamento de Construção Civil, Universidade Federal da Integração Latino-Americana, Foz do Iguaçu, Brasil \\ ${ }^{2}$ Laboratório de Biotecnologia Ambiental, Universidade Federal da Integração Latino-Americana, Foz do Iguaçu, Brasil
}

\section{RESUMO}

Este estudo avalia a influência da incorporação de nutrientes (extrato de levedura e acetado de cálcio) e do tipo de cura no processo de autocicatrização em amostras a base de cimento, empregando esporos da bactéria Bacillus subtilis (AP91) na água de amassamento. Para cinco argamassas $(1: 3: 0,48)$ e três tipos de cura (submersa, úmida com e sem aspersão de esporos bacterianos), foram produzidas amostras de 4x4x16 cm fissuradas e não fissuradas, para análise da autocicatrização e propriedades mecânicas, respectivamente. As fissuras foram monitoradas em estereomicroscópio aos 7, 14, 21 e 28 dias. Os resultados indicam que a adição da bactéria, com ou sem nutrientes, favoreceu a precipitação de $\mathrm{CaCO}_{3}$, promovendo fechamento pontual ou contínuo de fissuras e microfissuras, sendo mais favorável na cura úmida sem aspersão de esporos. Dessa forma, a autocicatrização biológica apresenta-se como uma ferramenta promissora em termos de manutenção de manifestações patológicas.

Palavras-chave: Autocura; agentes biológicos; carbonato de cálcio; materiais a base de cimento.

\begin{abstract}
This study considers the influence of the nutrient's incorporation (yeast extract and calcium acetate) and the cure type in the self-healing process of cement-based samples, using spores of the bacterium Bacillus subtilis (AP91) in the mixing water. 4x4x16 cm samples of five mortars (1: 3: 0.48) and three types of curing (submerged; wet with and without sprinkling of bacterial spores), cracked and non-cracked, were produced for the analysis of self-healing and mechanical properties. Cracks were monitored in a stereo microscope at 7, 14, 21 and 28 days. The results indicate the bacteria addition, with or without nutrients, improved the precipitation of $\mathrm{CaCO}_{3}$, promoting punctual or continuous closure of cracks and micro-cracks, being more favorable in wet curing without spore sprinkling. Thus, biological self-healing presents itself as a promising tool in terms of maintaining pathological manifestations.
\end{abstract}

Key words: Self-healing; biological agents; calcium carbonate; cement-based materials. 


\section{RESUMEN}

Este estudio evalúa la influencia de la incorporación de nutrientes (extracto de levadura y acetato de calcio) y del tipo de curado en el proceso de autocurado en muestras cementantes, utilizando esporas de la bacteria Bacillus subtilis (AP91) en el agua de amasado. Para cinco morteros (1: 3: 0.48) y tres tipos de curado (sumergido; húmedo con y sin aspersión de esporas bacterianas), se produjeron muestras de $4 \times 4 \times 16 \mathrm{~cm}$ agrietadas y no agrietadas para el análisis de autocuración y propiedades mecánicas, respectivamente. Las grietas fueron monitoreadas al microscopio a los 7 , 14, 21 y 28 días. Los resultados indican que la adición de las bacterias, con o sin nutrientes, favoreció la precipitación de $\mathrm{CaCO}_{3}$, promoviendo el cierre puntual o continuo de grietas y microgrietas, siendo más favorable en curado húmedo sin aspersión de esporas. Así, el autocurado biológico se presenta como una herramienta promisora en términos de mantenimiento de manifestaciones patológicas.

Palabras clave: Autocurado; agentes biológicos; carbonato de calcio; materiales a base de cemento.

\section{INTRODUÇÃO}

As fissuras são manifestações patológicas muito comuns no concreto, sendo ocasionadas por vários fatores, como sobrecargas, deformações devido a diferenças de temperatura, recalque diferencial, retração, além de reações expansivas. As fissuras podem ocasionar a redução da durabilidade, pois facilitam a entrada de água e/ou outros agentes agressivos que podem levar as armaduras à corrosão, desencadeando problemas estruturais às edificações de concreto armado. Na ausência de tratamentos rápidos e apropriados, o problema das fissuras pode evoluir, levando à necessidade de reparos onerosos, tanto sob o ponto de vista financeiro, como sustentável, dada a necessidade de utilização de mais materiais/recursos no processo (Van Tittelboom et al., 2010).

Estão em crescimento/desenvolvimento estudos que buscam encontrar soluções para correção de fissuras, de modo a tornar o concreto mais durável e sustentável, com menores investimentos ao logo do ciclo de vida, fazendo com que novas tecnologias sejam desenvolvidas. Uma das alternativas promissoras é a autocicatrização do concreto (Wiktor and Jonkers, 2011; SchwantesCezario, Nogueira and Toralles, 2017; Gulin, 2019). A autocicatrização do concreto ocorre naturalmente quando a água penetra nas fissuras e hidrata as porções remanescentes de cimento anidro (nominada de autocicatrização autógena). Este preenchimento é atribuído, quase que exclusivamente, à formação de carbonato de cálcio $\left(\mathrm{CaCO}_{3}\right)$, porém de forma limitada (Repette, 2011). Sendo assim, explorar o uso de algum material que precipite $\mathrm{CaCO}_{3} \mathrm{em}$ maior quantidade pode ser altamente vantajoso.

Neste sentido, existem agentes biológicos, especialmente bactérias, capazes de precipitar $\mathrm{CaCO}_{3}$ em seus processos metabólicos. A aplicação destes organismos em materiais cimentícios pode proporcionar o fechamento de fissuras reduzindo a porosidade e propiciando o aumento da resistência à compressão e da vida útil (De Belie and De Muynck, 2009; Wiktor and Jonkers, 2011; Gulin, 2019).

A incorporação desses agentes biológicos em materiais a base de cimento pode ocorrer basicamente de três maneiras: adicionados à água de amassamento; imersão das amostras em solução bacteriana; ou, por aspersão de solução em amostras já fissuradas (Vijay, Murmu and Deo, 2017). Quando incorporadas à água de amassamento, as bactérias podem ser aplicadas diretamente na matriz a base de cimento com ou sem formação de esporos (Jonkers et al., 2010), encapsuladas em materiais porosos como argila (Lucas et al., 2018) e perlita (Alazhari et al., 2018), ou hidrogel (Wang et al., 2018) e sílica gel (Wang et al., 2012). Jonkers e Thijssen (2010) sugerem, ainda, a adição das bactérias em matrizes com ar incorporado. 
$\mathrm{Na}$ autocicatrização biológica, $\mathrm{o} \mathrm{CaCO}_{3}$ é precipitado metabolicamente por bactérias inseridas no material cimentício. Para que este processo ocorra, devem também ser inseridos nutrientes, como o extrato de levedura, que servirão como fonte de energia para o desenvolvimento microbiano. Também, é importante a adição de fontes de cálcio, como acetato e/ou lactato de cálcio, precursores da precipitação de $\mathrm{CaCO}_{3}$ (Wang et al., 2018).

Apesar da grande variedade de bactérias existentes, nem todas são apropriadas para incorporação em matrizes cimentícias, onde tem-se um ambiente altamente alcalino, sem nutrientes e com oxigênio apenas nos poros e superfície, de modo a dificultar o crescimento bacteriano (Van Tittelboom et al., 2010). Sendo assim, é fundamental para a sobrevivência das bactérias nestes ambientes, que elas sejam capazes de formar esporos (estruturas extremamente resistentes), de modo a garantir a sobrevivência destes agentes à ação da mistura mecânica e às condições ambientais adversas de concretos e argamassas (Jonkers et al., 2010). Exemplos de bactérias que se encaixam neste contexto e que atendem à essas condições, são as do gênero Bacillus (SchwantesCezario, Nogueira and Toralles, 2017).

A incorporação de elementos (químicos, minerais, biológicos, etc.) na matriz cimentícia pode influenciar nas propriedades dos materiais a base de cimento (Monteiro, 2014). Dessa forma, com a adição de bactérias, seus precursores e nutrientes, faz-se necessário um estudo de como os mesmos atuarão, para garantir que as estruturas não percam qualidade, e atinjam o desempenho e durabilidade necessários (Schwantes-Cezario, Nogueira and Toralles, 2017).

Neste contexto, este estudo teve como objetivo analisar a influência da adição de esporos da linhagem Bacillus subtilis AP91 e seus nutrientes (extrato de levedura e acetato de cálcio), nas propriedades mecânicas de argamassas (resistência à tração na flexão e resistência à compressão) e na autocicatrização das fissuras submetidas a diferentes condições de cura (submersa, e úmida com aspersão e sem aspersão de esporos).

\section{MATERIAIS E MÉTODOS}

Este estudo foi dividido em três etapas principais. Na primeira etapa foi realizado o cultivo, esporulação e quantificação dos esporos da bactéria $B$. subtilis (AP91); na segunda foi realizado a produção e cura das argamassas a base de cimento; e na terceira foi realizado os ensaios experimentais referentes a análise das fissuras e as propriedades mecânicas das argamassas.

\subsection{Microrganismo e condição de crescimento}

A linhagem B. subtilis (AP91), disponibilizada pela Empresa Brasileira de Pesquisa Agropecuária (Embrapa), foi usada neste estudo devido sua capacidade comprovada de precipitar $\mathrm{CaCO}_{3}$ (Schwantes-Cezario et al., 2017). Para verificar a precipitação de carbonato de cálcio a B. subtilis (AP91) foi inoculada e cultivada em placas de Petri contendo meio B4 (4g L ${ }^{-1}$ de extrato de levedura, $14 \mathrm{~g} \mathrm{~L}^{-1}$ de ágar bacteriológico, 2,5 $\mathrm{mL} \mathrm{L}^{-1}$ de solução de vermelha fenol, $12,5 \mathrm{~mL} \mathrm{~L}^{-1} \mathrm{de}$ glicose a $40 \%$ e $25 \mathrm{~mL} \mathrm{~L}^{-1}$ de acetato de cálcio a 10\%) com o indicador de $\mathrm{pH}$ vermelho de fenol em três condições diferentes: (a) padrão B4; (b) ácido B4, tamponado a pH 7,0; e (c) alcalina B4, tamponada a $\mathrm{pH} 8,2$. O pH de cada meio de cultivo foi mantido tamponando utilizando tris $1,2 \%$ $(\mathrm{p} / \mathrm{v})$. As placas foram incubadas na estufa (BOD) a $37^{\circ} \mathrm{C}$ durante 7 dias (Marvasi et al., 2010; Marvasi, Davila-Vazquez and Martinez, 2013).

Após o crescimento, a linhagem foi inoculada e cultivada em tubos Falcon de $15 \mathrm{~mL}$ contento meio de cultura Mueller Hinton (MH) líquido, constituído por $17 \mathrm{~g} \mathrm{~L}^{-1}$ de peptona de caseína, $2 \mathrm{~g} \mathrm{~L}^{-1}$ de peptona de carne e 1,5 $\mathrm{g} \mathrm{L}^{-1}$ de amido, com $\mathrm{pH}$ final 7,3 $\pm 0,1$. Em seguida foram colocadas no agitador Shaker por 66 horas a uma rotação de $130 \mathrm{rpm}$ e uma temperatura média de $37^{\circ} \mathrm{C}$. Após o período de agitação, a solução com as bactérias foi lavada para remover o meio de cultura e obter uma solução mais concentrada de bactérias. Para isto, o meio de cultura foi centrifugado em tubos 
Falcon durante 20 minutos a uma rotação de $3600 \mathrm{rpm}$, onde o sobrenadante foi removido e substituído por uma solução salina de $\mathrm{NaCl}$ a $0,85 \%$. O procedimento foi repetido duas vezes $(\mathrm{n}=2)$. Em seguida, a solução salina contendo bactérias foi armazenada por dois dias à temperatura de $8{ }^{\circ} \mathrm{C}$ para induzir a formação de esporos (Schwantes-Cezario et al., 2018).

A quantificação dos esporos bacterianos cultivados em meio de cultura $\mathrm{MH}$ foi realizada com o auxílio do espectrofotômetro com leitura a $600 \mathrm{~nm}$. Para o teste foram utilizadas duas alíquotas de $1 \mathrm{~mL}$ (Khaliq and Ehsan, 2016), o controle com solução salina a $0,85 \%$ e as bactérias crescidas em solução de $\mathrm{MH}$, diluída em solução salina a $0,85 \%$. A concentração de bactérias no meio foi calculada pela equação (1) aplicada por Ramachandran; Ramakrishnan; Bang (2001).

$$
Y=\left(8,59 X 10^{7}\right) \times\left(X^{1,3627}\right)
$$

onde: $\mathrm{X}=$ absorvência (a); $\mathrm{Y}=$ concentração de esporos por $\mathrm{mL}$.

O procedimento foi realizado três vezes adotando o valor médio da concentração de bactérias (Kim et al., 2013). A partir da concentração encontrada, os cálculos de diluição foram feitos para atingir uma concentração de $10^{6}$ esporos $\mathrm{mL}^{-1}$. A diluição foi feita em água destilada. A suspensão com esporos bacterianos foi subsequentemente mantida em geladeira a $4{ }^{\circ} \mathrm{C}$ até ser utilizada na mistura do material cimentício (Jonkers et al., 2010).

\subsection{Argamassa}

As amostras de argamassa (Tabela 1) foram produzidas utilizando os seguintes materiais: cimento Portland de alta resistência inicial (CPV ARI), agregado fino (areia natural), água, esporos de $B$. subtilis (B) diluídos em água, acetato de cálcio (A) e extrato de levedura (E). Os esporos das bactérias, em uma concentração de $10^{6}$ esporos $\mathrm{mL}^{-1}$, o acetato de cálcio e o extrato de levedura foram adicionados na água de mistura em diferentes combinações, dessa forma produzindo cinco variações de argamassas. A proporção de cimento-areia utilizada foi de 1:3, em massa, e a relação água-cimento $(\mathrm{a} / \mathrm{c})$ foi de 0,48 (Tabela 2$)$.

Tabela 1 - Nomenclatura das argamassas

\begin{tabular}{|l|l|}
\hline Nomenclatura & Composição \\
\hline $\mathrm{R}$ & Argamassa de referência produzida com cimento, areia e água \\
\hline $\mathrm{B}$ & Argamassa com adição de esporos na água de mistura \\
\hline $\mathrm{B}+\mathrm{A}$ & Argamassa com adição de esporos + acetato de cálcio na água de mistura \\
\hline $\mathrm{B}+\mathrm{E}$ & Argamassa com adição de esporos + extrato de levedura na água de mistura \\
\hline $\mathrm{B}+\mathrm{A}+\mathrm{E}$ & Argamassa com adição de esporos + acetato de cálcio + extrato de levedura na água de mistura \\
\hline
\end{tabular}

Tabela 2 - Proporção de mistura das argamassas com agentes biológicos

\begin{tabular}{|l|c|c|c|c|c|c|}
\hline \multirow{2}{*}{ Argamassas } & \multicolumn{3}{|c|}{ Quantidade de materiais (g) } & \multirow{2}{*}{$\begin{array}{c}\text { Esporos } \\
\text { B. subtilis } \text { mL }^{-1}\end{array}$} & \multicolumn{2}{c|}{ Nutrientes (\%) } \\
\cline { 2 - 3 } & Cimento & Areia & Água & & B $^{* *}$ \\
\hline $\mathrm{R}$ & 900 & 2700 & 432 & - & - & - \\
\hline $\mathrm{B}$ & 900 & 2700 & 432 & $10^{6}$ & - & - \\
\hline $\mathrm{B}+\mathrm{A}$ & 900 & 2700 & 432 & $10^{6}$ & 1 & - \\
\hline $\mathrm{B}+\mathrm{E}$ & 900 & 2700 & 432 & $10^{6}$ & - & 1 \\
\hline $\mathrm{B}+\mathrm{A}+\mathrm{E}$ & 900 & 2700 & 432 & $10^{6}$ & 1 & 1 \\
\hline
\end{tabular}

*Concentração de acetato de cálcio em relação a concentração de cimento (Jonkers et al., 2010).

**Concentração de extrato de levedura em relação a concentração de cimento (Jonkers et al., 2010).

O procedimento de mistura das argamassas foi realizado com misturador portátil, onde primeiro foram adicionados os componentes secos (cimento, areia, acetato de cálcio e extrato de levedura) misturando-os manualmente. Depois, a água com a solução de esporos foi sendo adicionada aos 
poucos, seguida de nova mistura manual. Por fim, a mistura foi homogeneizada mecanicamente por um minuto, depois misturada manualmente para raspar a argamassa aderida na superfície lateral do balde e novamente misturada mecanicamente por mais dois minutos.

Foram produzidas amostras de argamassas com e sem armadura $(4,8 \mathrm{~mm}$ de diâmetro e $15 \mathrm{~cm}$ de comprimento, posicionada a $1 \mathrm{~cm}$ da base) usando moldes prismáticos de 4x4x16 $\mathrm{cm}$ de acordo com a NBR 13279 (2005). As amostras foram desmoldadas após 48 horas e armazenadas no laboratório em cura úmida envoltas por uma manta de drenagem de solo sob condições de temperatura e umidade não controladas. As amostras de argamassa com armadura (usadas para análise da recuperação de fissuras) foram submetidas a cura úmida por 7 dias (até a idade de abertura das fissuras). As amostras de argamassa sem armadura (usadas para a avaliação da resistência à tração na flexão de 3 pontos e à compressão) foram submetidas a cura úmida por 28 dias. $\mathrm{O}$ procedimento de fissuração consistiu na aplicação, constante e lenta, de carga em amostras de argamassa com armadura após 7 dias de cura até o surgimento da primeira fissura sendo descarregada em seguida, por meio do ensaio de tração na flexão de 3 pontos utilizando uma prensa hidráulica (Figura 1).

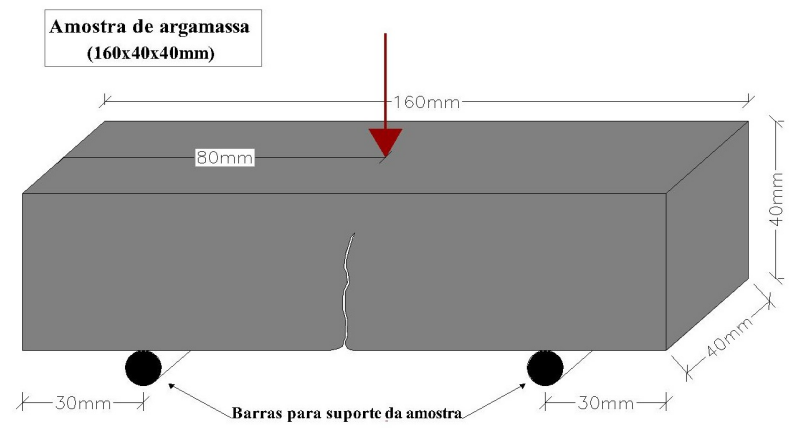

Figura 1 - Ensaio de tração na flexão de 3 pontos

Após a fissuração, as amostras foram submetidas a três condições diferentes de cura: submersa em água; úmida envolta em manta de drenagem com e sem aspersão de solução com esporos (Tabela 3). A solução com esporos foi aspergida uma vez por semana, ao longo de 7, 14, 21 e 28 dias para o monitoramento do preenchimento das fissuras.

Tabela 3 - Programa experimental

\begin{tabular}{|c|c|c|c|c|c|c|}
\hline \multirow[b]{2}{*}{ Grupo } & \multirow[b]{2}{*}{ CPs } & \multicolumn{3}{|c|}{ Número de CPs quanto ao tipo de cura } & \multirow{2}{*}{$\begin{array}{c}\text { Ensaio } \\
\text { mecânico } \\
\text { (dias)* }\end{array}$} & \multirow{2}{*}{$\begin{array}{l}\text { Monitoramento } \\
\text { das fissuras } \\
\text { (dias) } * *\end{array}$} \\
\hline & & Submersa & $\begin{array}{c}\text { Úmida sem } \\
\text { aspersão }\end{array}$ & $\begin{array}{c}\text { Úmida com } \\
\text { aspersão }\end{array}$ & & \\
\hline \multirow{2}{*}{ REF } & NA & - & 3 & - & 28 & - \\
\hline & A & 1 & 1 & 1 & - & $0,7,14,21,28$ \\
\hline \multirow{2}{*}{ B } & NF & - & 3 & - & 28 & - \\
\hline & NA & 1 & 1 & 1 & - & $0,7,14,21,28$ \\
\hline \multirow{2}{*}{$\mathrm{B}+\mathrm{A}$} & NA & - & 3 & - & 28 & - \\
\hline & A & 1 & 1 & 1 & - & $0,7,14,21,28$ \\
\hline \multirow{2}{*}{$B+E$} & NA & - & 3 & - & 28 & - \\
\hline & $\mathrm{A}$ & 1 & 1 & 1 & - & $0,7,14,21,28$ \\
\hline \multirow{2}{*}{$\mathrm{B}+\mathrm{A}+\mathrm{E}$} & NA & - & 3 & - & 28 & - \\
\hline & $\mathrm{A}$ & 1 & 1 & 1 & - & $0,7,14,21,28$ \\
\hline
\end{tabular}

Onde: CPs: corpos de prova; NA: não armado; A: armado; B: bactéria B. subtilis; A: acetato de cálcio; E: extrato de levedura

* Data para realização dos ensaios de resistência à tração na flexão de 3 pontos e à compressão.

** Datas para realização do monitoramento das fissuras.

\subsection{Métodos experimentais}

\subsubsection{Análise das fissuras}


O monitoramento visual das fissuras durante o período de cura, aos 0, 7, 14, 21 e 28 dias após fissuração, foi realizado por imagens obtidas em um Estereomicroscópio Óptico (da marca Zeiss Discovery.V12) com lentes Zeiss PlanApo S 1.0x FWD de $60 \mathrm{~mm}$, ligado a uma câmera Zeiss Axiocam 105 com ampliação de até 100x e rodando o software AxioVision SE64.

As análises visuais do preenchimento das fissuras foram realizadas sempre com o mesmo fragmento central, de 1,4 cm de comprimento, de cada amostra de argamassa (Figura 2). Foram analisadas três amostras de cada grupo de argamassa $(n=3)$, onde cada amostra foi submetida a diferentes condições de cura (submersa, úmida sem aspersão de esporos e úmida com aspersão de esporos).

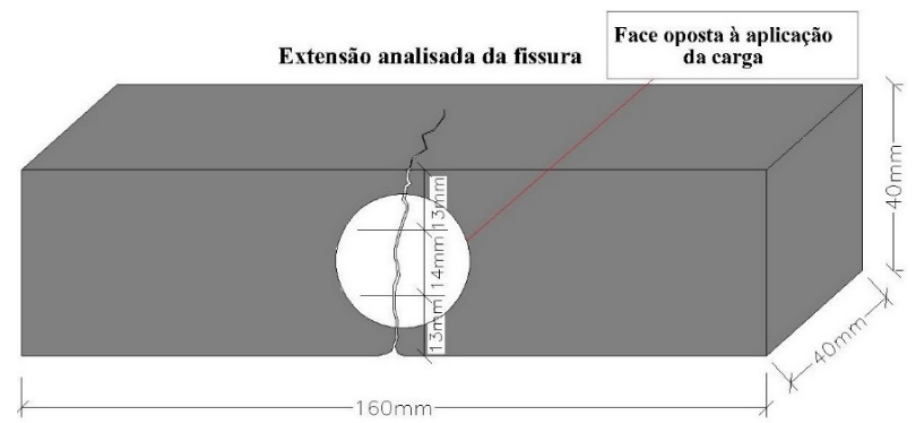

Figura 2 - Seguimento da fissura analisado

Os ensaios de resistência à tração na flexão de 3 pontos e à compressão foram realizados com amostras prismáticas de argamassa sem armadura de 4x4x16 cm com 28 dias de idade $(\mathrm{n}=3$ e 6 , respectivamente) de acordo com a NBR 13279 (2005).

\section{RESULTADOS E DISCUSSÕES}

\subsection{Análise das fissuras}

As imagens obtidas no monitoramento das fissuras para os três processos de cura em estudo são mostradas nas Tabelas 4, 5 e 6 . Como pode-se observar as fissuras apresentam espessuras diferentes, com valores que variam de 0,17 a $0,88 \mathrm{~mm}$, isso se deve a dificuldade encontrada durante o ensaio de fissuração para produzir fissuras de tamanhos similares. Para minimizar as diferentes larguras entre as fissuras a autora Hollmann (2020) recomenda a fissuração de um número grande de amostras, a fim de possibilitar a seleção daquelas que apresentam fissuras com espessuras similares.

Durante a análise do fechamento das fissuras, observou-se que o tamanho inicial da largura da fissura teve influência no processo de biorecuperação das mesmas. Amostras com fissuras de pequenas aberturas (inferior a $0,25 \mathrm{~mm}$ ) tiveram mais sucesso no processo de autocicatrização, para o período avaliado. Estudos realizados por $\mathrm{Xu}$ e Yao (2014) afirmam que as larguras das fissuras de 0,1 a $0,4 \mathrm{~mm}$ foram parcialmente seladas, por precipitados minerais formados pelo metabolismo bacteriano. Luo, Qian e Li (2015) afirmam que as fissuras com larguras médias de 0,1-0,3 mm e 0,3-0,5 mm foram quase totalmente curadas $(\geq 85 \%$ e 50 a $70 \%$ de reparo, respectivamente), e $0,5-0,8 \mathrm{~mm}$ foram parcialmente curadas $(\leq 30 \%$ de reparo).

Outro fator observado que influenciou no processo de recuperação das fissuras foi o tipo de cura que as amostras foram submetidas. Amostras submetidas à cura submersa (Tabela 4) e amostras submetidas à cura úmida, sem aspersão de esporos (Tabela 5) apresentaram maiores taxa de sucesso na precipitação de cristais na região fissurada. 
Tabela 4 - Monitoramento por imagem das fissuras em cura submersa (ampliação de 8x em estereomicroscópio óptico com câmera acoplada)

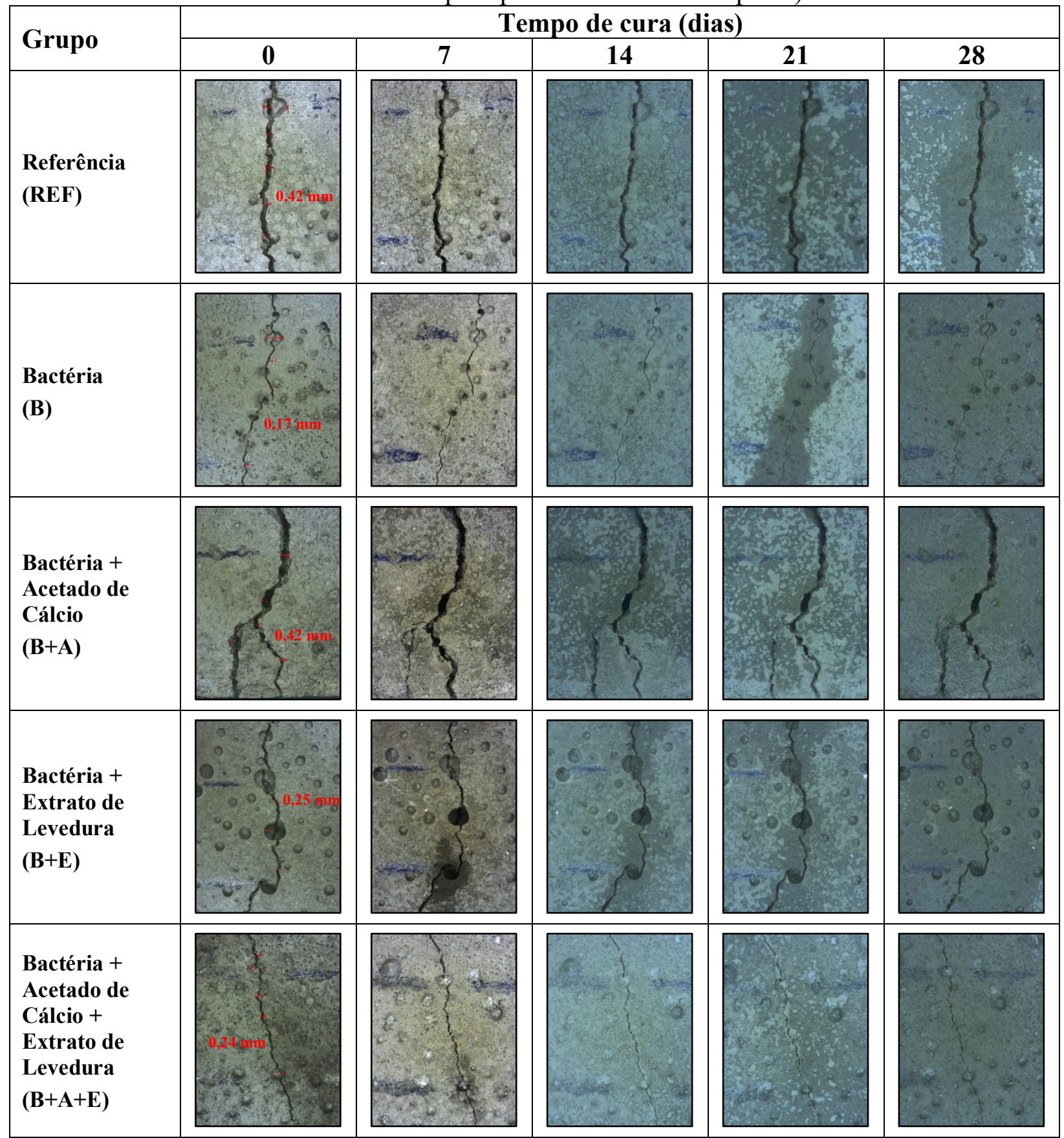

Na Tabela 4, constatou-se a precipitação de carbonato de cálcio nas amostras produzidas somente com esporos bacterianos (B), com esporos mais acetato de cálcio (B+A) e com esporos mais acetato de cálcio mais extrato de levedura $(\mathrm{B}+\mathrm{A}+\mathrm{E})$ quando submetidas a cura submersa.

Nas amostras submetidas à cura úmida sem aspersão de esporos (Tabela 5), constatou-se $\mathrm{CaCO}_{3}$ precipitado nas amostras produzidas somente com esporos bacterianos (B), com esporos mais extrato de levedura $(\mathrm{B}+\mathrm{E})$ e com esporos mais acetato de cálcio mais extrato de levedura $(\mathrm{B}+\mathrm{A}+\mathrm{E})$. Já nas amostras submetidas à cura úmida com aspersão de esporos (Tabela 6), a precipitação de carbonato foi observada na amostra produzida com esporos mais extrato de levedura $(B+E)$. 
Tabela 5 - Monitoramento por imagem das fissuras em cura úmida sem aspersão de esporos (ampliação de 8x em estereomicroscópio óptico com câmera acoplada)

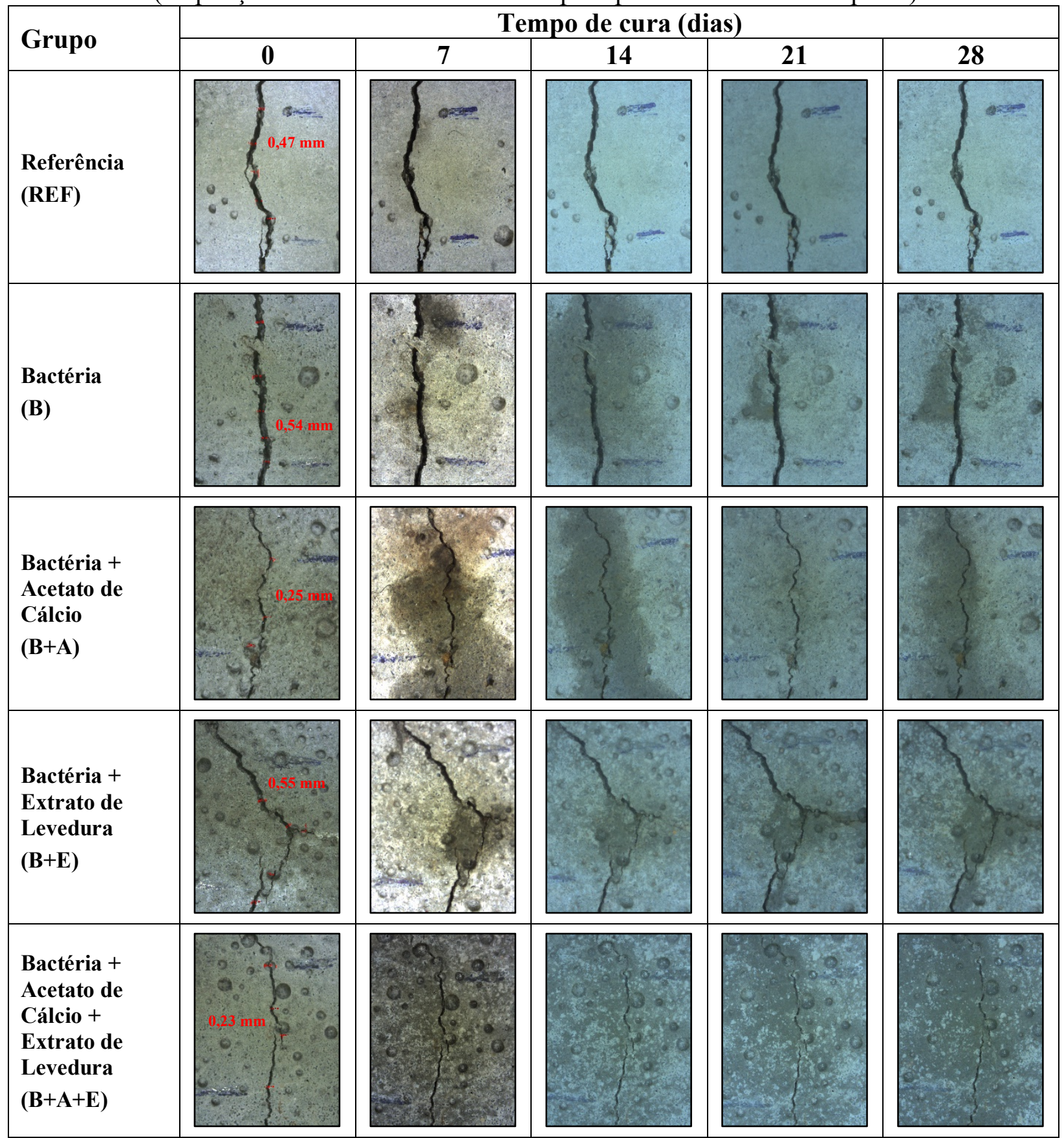

A visualização do fechamento das fissuras por meio da precipitação de cristais pode ser mais bem observada nos detalhes mostrados nas Figuras 3, 4 e 5, em que se observam cicatrizações pontuais e/ou contínuas. A recuperação da fissura nas amostras submetidas à cura submersa (Figura 3) ocorreu na região de microfissuras de forma pontual para a amostra $\mathrm{B}$ e contínua para a $\mathrm{B}+\mathrm{A}$. 
Tabela 6 - Monitoramento por imagem das fissuras em cura úmida com aspersão de esporos (ampliação de 8x em estereomicroscópio óptico com câmera acoplada)

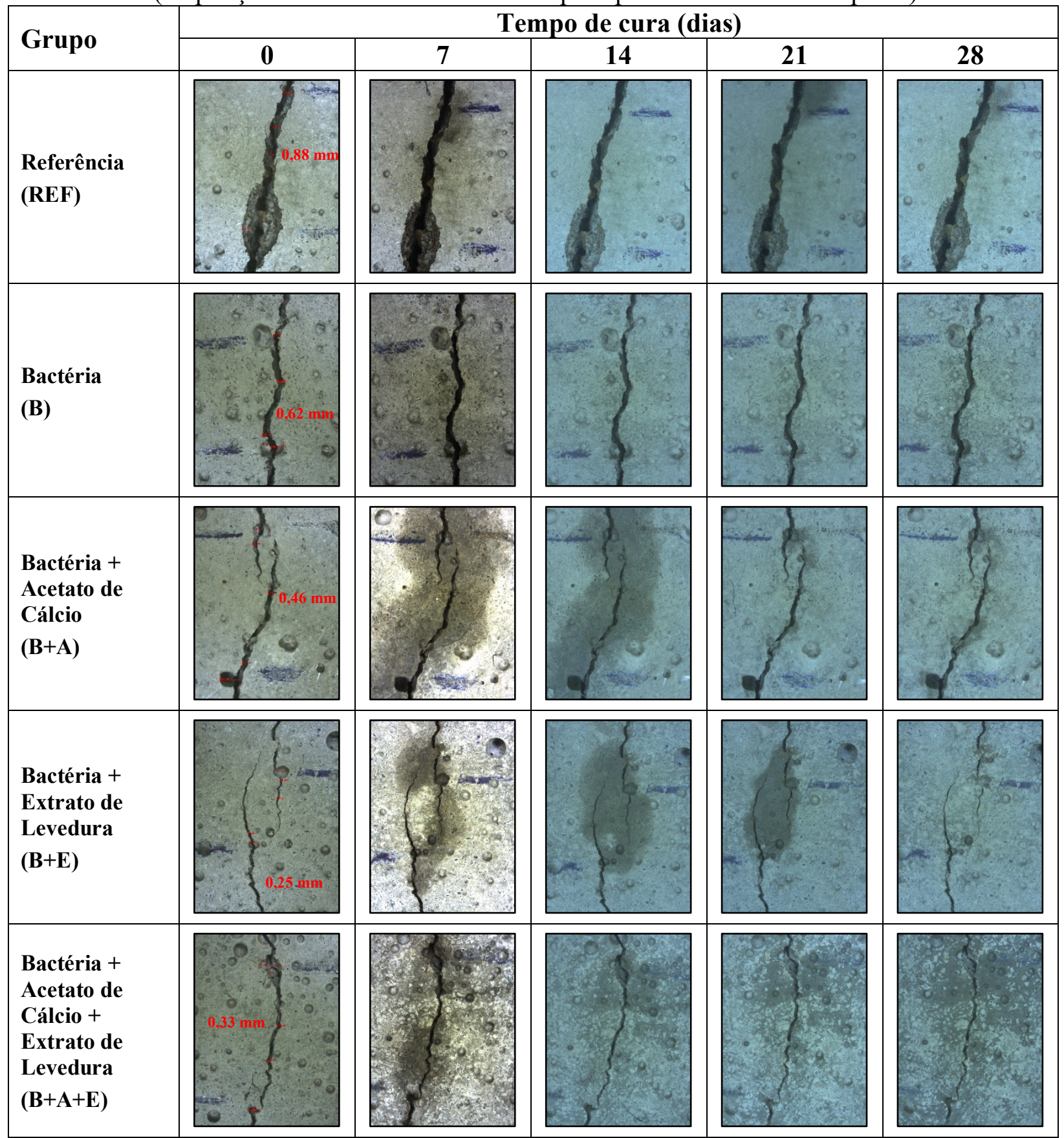

$\mathrm{Na}$ amostra $\mathrm{B}+\mathrm{A}+\mathrm{E}$ verifica-se uma redução da abertura da fissura aos 28 dias, com precipitação de cristas na região de fissura de forma pontual e contínua. Para a cura úmida, sem aspersão de esporos (Figura 4), observa-se que a precipitação de carbonato ocorreu de forma contínua na região de microfissuras nas amostras $\mathrm{B}$ e $\mathrm{B}+\mathrm{E}$, e na amostra $\mathrm{B}+\mathrm{A}+\mathrm{E}$ ocorreu na região de fissura de forma pontual e na região de microfissura de forma contínua. Em relação à cura úmida, com aspersão de esporos (Figura 5), verifica-se que a precipitação de carbonato ocorreu na região de fissura de forma pontual e na região de microfissura de forma contínua na amostra $\mathrm{B}+\mathrm{E}$.

Tanto nas amostras submetidas à cura submersa quanto nas amostras submetidas a cura úmida, sem aspersão de esporos, o melhor resultado em relação à recuperação das fissuras foi obtido quando adicionado três componentes juntos: bactéria como agente autocicatrizante; acetato de cálcio como 
fonte de cálcio na precipitação de cristais; e, extrato de levedura como fonte de nutriente para o crescimento da bactéria na matriz cimentícia. Os estudos desenvolvidos por Lucas et al. (2018) e Jang et al. (2020), relatam um ganho de eficiência na cicatrização de fissuras ao adicionar na mistura do concreto uma combinação de três componentes, bactéria do gênero Bacillus, lactato de cálcio e extrato de levedura, em comparação com o concreto sem adição destes componentes.

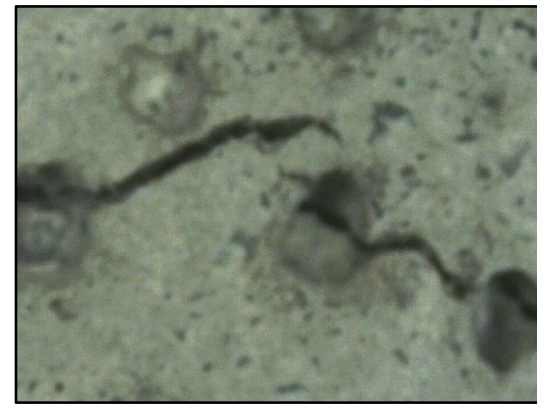

Argamassa B - 0 dias

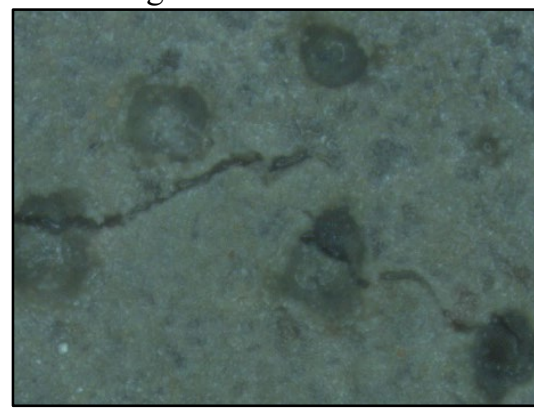

Argamassa B - 28 dias

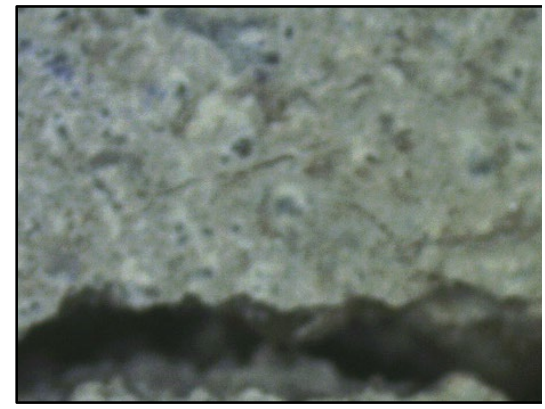

Argamassa $\mathrm{B}+\mathrm{A}-0$ dias

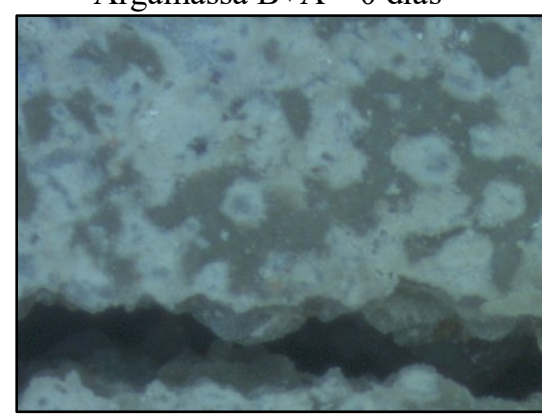

Argamassa $\mathrm{B}+\mathrm{A}-28$ dias

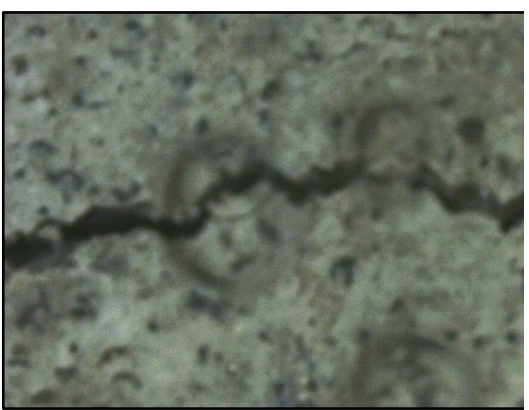

Argamassa $\mathrm{B}+\mathrm{A}+\mathrm{E}-0$ dias

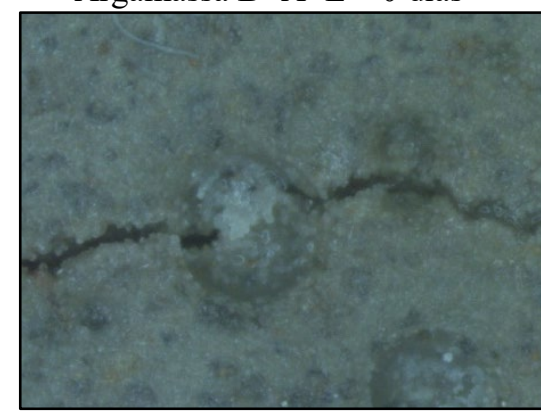

Argamassa $\mathrm{B}+\mathrm{A}+\mathrm{E}-28$ dias

Figura 3 - Detalhe da região recuperada de amostras submetidas à cura submersa (ampliação de 30x)

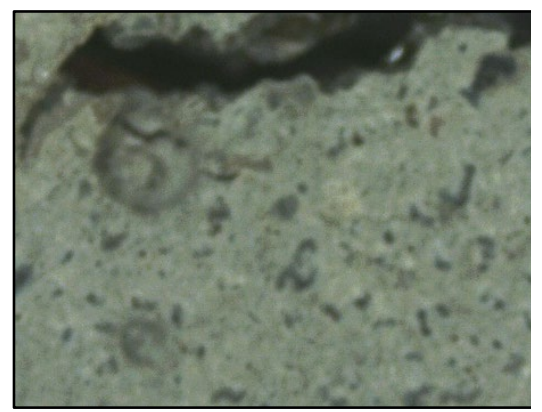

Argamassa B - 0 dias

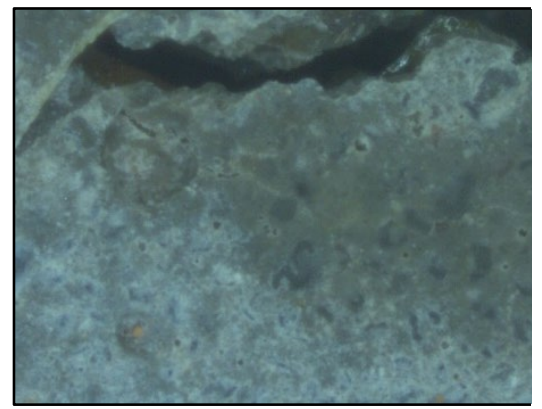

Argamassa B - 28 dias

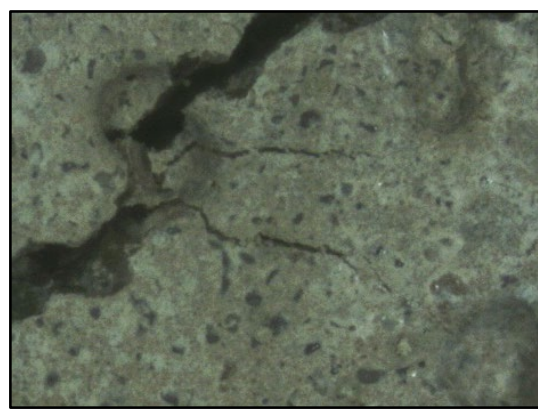

Argamassa $\mathrm{B}+\mathrm{E}-0$ dias

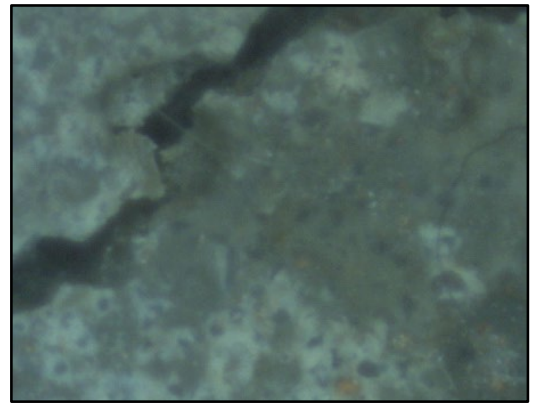

Argamassa B+E - 28 dias

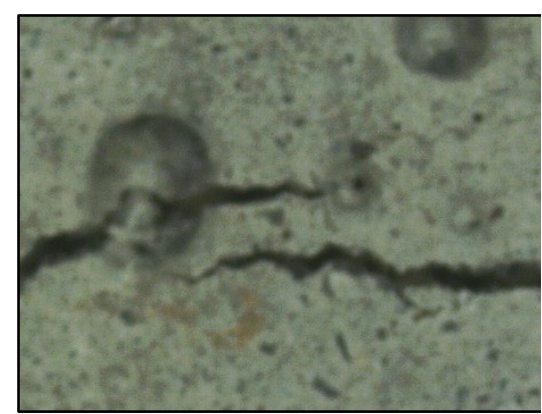

Argamassa $\mathrm{B}+\mathrm{A}+\mathrm{E}-0$ dias

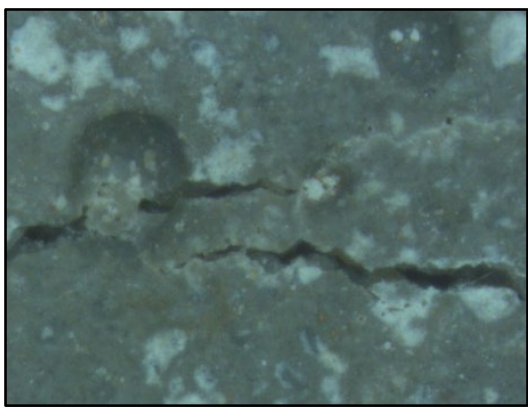

Argamassa $\mathrm{B}+\mathrm{A}+\mathrm{E}-28$ dias

Figura 4 - Detalhe da região recuperada de amostras submetidas à cura úmida sem aspersão de esporos (ampliação de 30x) 


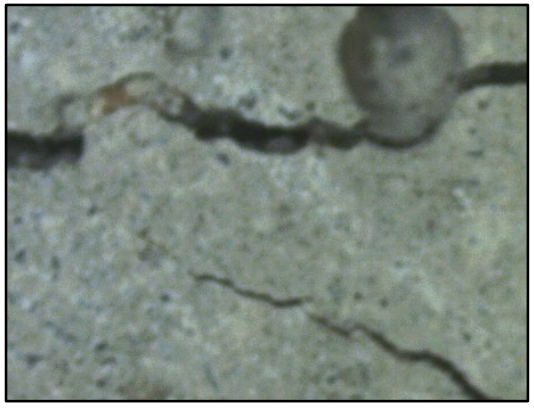

Argamassa $\mathrm{B}+\mathrm{E}-0$ dias

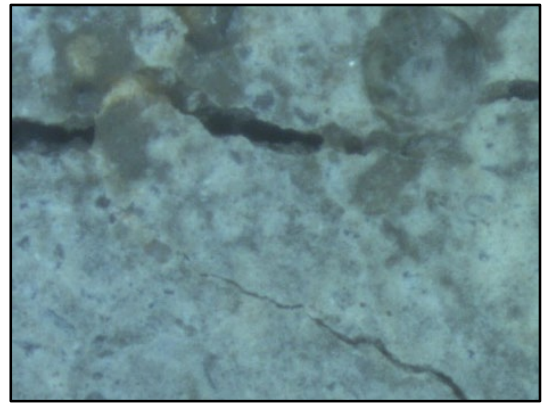

Argamassa B+E - 28 dias

Figura 5 - Detalhe da região recuperada de amostras submetidas à cura úmida com aspersão de esporos (ampliação de 30x)

Já entre as amostras submetidas a cura úmida com aspersão de esporos, o melhor resultado em relação à recuperação das fissuras foi obtido quando adicionado dois componentes em conjunto: bactéria como agente autocicatrizante; e, extrato de levedura como fonte de nutriente para o crescimento da bactéria na matriz cimentícia. Segundo estudos desenvolvidos por Naguyen et al. (2019), as amostras de concreto produzidos com a adição de bactéria B. subtilis combinado com peptona e extrato de levedura na mistura apresentaram maior eficiência de cura das fissuras em comparação a amostras de concreto controle.

O processo de autocicatrização das fissuras por meio da biodeposição de $\mathrm{CaCO}_{3}$ por bactérias é influenciado pela presença destes microrganismos e dos nutrientes na região da fissura (Wiktor and Jonkers, 2011). Sendo assim, algumas fissuras talvez não tenham apresentado precipitação de carbonato de cálcio, devido à ausência ou insuficiência de microrganismos e/ou nutrientes no local na região fissurada. Isso se deve à distribuição dos microrganismos e/ou nutrientes não ocorrer de forma homogênea durante a produção das amostras de argamassa, dificultando a análise dos resultados. Outra questão a ser considerada é a não ativação dos esporos bacterianos no período de estudo, que é influenciada pela temperatura do ambiente ideal que varia de $20{ }^{\circ} \mathrm{C}$ a $37{ }^{\circ} \mathrm{C}$ (Arunachalam et al., 2010), pela disponibilidade de umidade (De Koster et al., 2015) e de oxigênio (Bhaskar et al., 2017) nas fissuras, e pelo pH ideal da matriz cimentícia em torno de 9 (PachecoTorgal and Labrincha, 2013).

Ainda, a análise do fechamento das fissuras deve levar em consideração a abertura inicial da fissura. Segundo Jonkers et al. (2010) o uso de bactérias na biodeposição de $\mathrm{CaCO}_{3}$ resultará no reparo autônomo de fissuras com larguras menores que $1 \mathrm{~mm}$. Estudos realizados por Vashisht e Shukla (2020) comprovaram por análise visual a autocura de macro fissuras com larguras de até 0,48 mm.

\subsection{Propriedades mecânicas das argamassas}

Em relação a resistência à tração na flexão observa-se na Figura 6 que as amostras de controle (B, $\mathrm{B}+\mathrm{A}, \mathrm{B}+\mathrm{E}$ e $\mathrm{B}+\mathrm{A}+\mathrm{E})$ apresentaram valores de resistência maiores que a amostra de referência. Entre as amostras de controle o melhor resultado $(6,95 \mathrm{MPa})$ foi apresentado pela argamassa com esporos e extrato de levedura $(\mathrm{B}+\mathrm{E})$ adicionados à mistura, correspondendo a um incremento de resistência à tração de $27 \%$ em relação à de referência. Já em relação a resistência à compressão, observa-se que as amostras de controle $(B, B+A$ e $B+E)$ apresentaram valores de resistência inferiores à amostra de referência. Entre as argamassas avaliadas o melhor resultado $(31,86 \mathrm{MPa})$ foi apresentado pela argamassa com esporos mais acetato de cálcio mais extrato de levedura $(\mathrm{B}+\mathrm{A}+\mathrm{E})$ adicionados à mistura. A resistência à compressão desta mistura foi similar à de referência (0,28\% inferior), estando na faixa de variação típica do ensaio. 


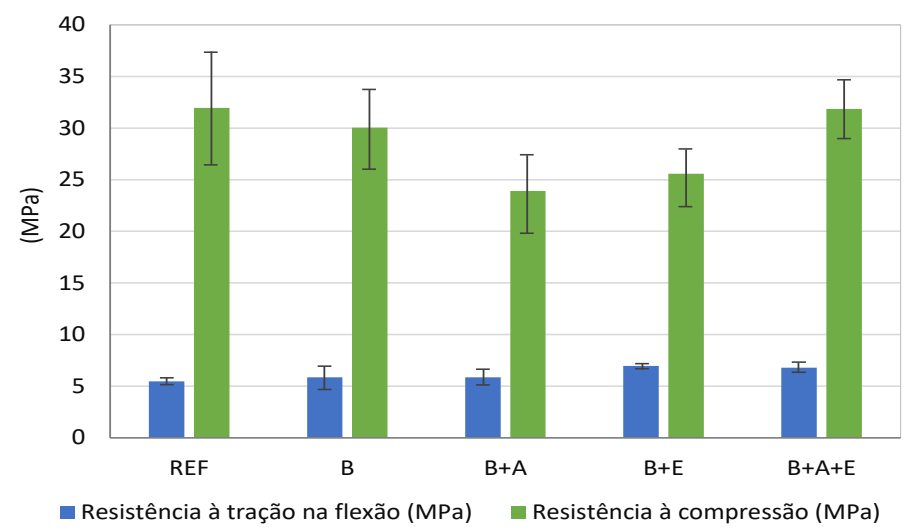

Figura 6 - Efeito da linhagem B. subtilis AP91 nas propriedades mecânicas após 28 dias de cura

Nain et al. (2019) relatam que a resistência à tração do concreto produzido com adição combinada de bactéria $B$. subtilis e caldo nutriente composto por peptona, cloreto de sódio, extrato de levedura e extrato de carne, apresentou melhores resultados em comparação ao concreto controle. Estudos realizados por Jonkers et al. (2010), demonstraram que as amostras de pasta cimento produzidas com adição de bactérias Bacillus pseudofirmus, acetato de cálcio e extrato de levedura, separadamente, apresentaram menores valores de resistência à compressão em comparação com a amostra de pasta cimento controle. Outra pesquisa desenvolvida por Pei et al. (2013) obteve valores inferiores de resistência à compressão de argamassa produzidas com bactéria Bacillus subtilis, ureia e cloreto de Ca cominados, em comparação com a argamassa controle. A incorporação de compostos orgânicos e inorgânicos, como o extrato de levedura e o acetato de cálcio, respectivamente, ao concreto é um pré-requisito para a autocura, porém ambos podem resultar em perda indesejável da resistência (Ramachandran, Ramakrishnan and Bang, 2001; Jonkers and Schlangen, 2007).

\section{CONCLUSÕES}

Os resultados deste estudo mostram que a adição da bactéria $B$. subtilis, com ou sem adição de nutrientes (acetato de cálcio + extrato de levedura) isolados ou combinados à matriz cimentícia, propiciou a precipitação de carbonatado de cálcio $\left(\mathrm{CaCO}_{3}\right)$, promovendo fechamento pontual ou contínuo de fissuras e microfissuras. Amostras produzidas com a combinação dos três componentes (esporos + acetato de cálcio + extrato de levedura) incorporados apresentaram os melhores resultados em relação à cicatrização das fissuras.

Constatou-se que a abertura inicial da fissura da amostra tem influência neste processo. Foi observada, aos 28 dias de análise, a formação de cristais de forma pontual em fissuras de maior dimensão e contínua na região de microfissuras.

Para os três tipos de cura empregados (submersa, úmida com e sem aspersão de esporos), constatou-se a precipitação de carbonatos na região fissurada. A incorporação de esporos bacterianos (B. subitilis) e nutrientes (acetato de cálcio e extrato de levedura) em amostras submetidas à cura úmida, sem aspersão de esporos, apresentaram os melhores resultados em relação à cicatrização das fissuras.

A aplicação da bactéria com acetato de cálcio e extrato de levedura, até $1 \%$ em relação à massa de cimento, resultou em ganho de resistência à tração na flexão. Já a aplicação de esporos bacterianos isolados (B) ou em combinação com acetato de cálcio e extrato de levedura (B+A+E) em até 1\% de cada em relação à massa de cimento, não resultou em perda significativa de resistência à compressão das amostras. Já a aplicação da bactéria com acetato de cálcio $(B+A)$ e/ou extrato de levedura $(\mathrm{B}+\mathrm{E})$ resultou em perdas indesejadas de resistência à compressão. 
A biorecuperação de materiais a base de cimento é um tema de pesquisa recente e desafiador, exigindo estudos interdisciplinares e complexos. A viabilidade desta solução tecnológica ainda requer estudos, pois ainda existem muitas variáveis (tipo e quantidade de bactéria, tipo e quantidade de nutrientes, tipo de cura, condições adequadas para a ativação dos esporos) que interferem na precipitação de $\mathrm{CaCO}_{3}$ e que suas influências não são claras.

\section{AGRADECIMIENTOS}

Os autores agradecem à Empresa Brasileira de Pesquisa Agropecuária (Embrapa) por disponibilizar a linhagem da bactéria B. subtilis (AP91) para o desenvolvimento desta pesquisa. Ao LADEMA, ao laboratório de Biodiversidade da Unila e à Fundação Araucária pelo suporte à pesquisa experimental. À Unila pela bolsa de mestrado e fomento à pesquisa pelo edital PRPPG No 137.

\section{REFERÊNCIAS}

Alazhari, M. et al. (2018) 'Application of expanded perlite encapsulated bacteria and growth media for self-healing concrete', Construction and Building Materials, 160, pp. 610-619. doi: 10.1016/j.conbuildmat.2017.11.086.

Arunachalam, K. D. et al. (2010) 'Studies on the characterisation of Biosealant properties of Bacillus sphaericus', International Journal of Engineering Science and Technology, 2(3), pp. 270-277.

ASSOCIAÇÃO BRASILEIRA DE NORMAS TÉCNICAS (2005) 'NBR 13279 Argamassa para assentamento e revestimento de paredes e tetos - Determinação da resistência à tração na flexão e à compressão', Associação Brasileira de Normas Técnicas, pp. 1-9.

De Belie, N. and De Muynck, W. (2009) 'Crack repair in concrete using biodeposition', Concrete Repair, Rehabilitation and Retrofitting II - Proceedings of the 2nd International Conference on Concrete Repair, Rehabilitation and Retrofitting, ICCRRR, 2, pp. 291-292. doi:

10.1201/9781439828403.ch107.

Bhaskar, S. et al. (2017) 'Effect of self-healing on strength and durability of zeolite-immobilized bacterial cementitious mortar composites', Cement and Concrete Composites, 82, pp. 23-33. doi: 10.1016/j.cemconcomp.2017.05.013.

Gulin, L. B. (2019) Viabilidade do Uso de Sílica de Sílica Gel na Imobilização da Bactéria Bacillus subtilis para Materiais Cimentícios Autocicatrizantes. Universidade Tecnológica Federal do Paraná.

Hollmann, C. F. (2020) Avaliação da influência de aditivos cristalizantes na resistência à penetração de íons cloreto em concretos fissurados. Universidade Federal do Rio Grande do Su.

Jang, I. et al. (2020) 'Effects of spray-dried co-cultured bacteria on cement mortar', Construction and Building Materials, 243, pp. 1-9. doi: 10.1016/j.conbuildmat.2020.118206.

Jonkers, H. M. et al. (2010) 'Application of bacteria as self-healing agent for the development of sustainable concrete', Ecological Engineering, 36(2), pp. 230-235. doi:

10.1016/j.ecoleng.2008.12.036. 
Jonkers, H. M. and Schlangen, E. (2007) 'Self-healing of cracked concrete: A bacterial approach', Proceedings of the 6th International Conference on Fracture Mechanics of Concrete and Concrete Structures, 3, pp. 1821-1826.

Jonkers, H. M. and Thijssen, A. (2010) 'Bacteria Mediated of Concrete Strutures', 2nd International Symposium on Service Life Design for Infrastructure 4-6 October 2010, Delft, The Netherlands, (October), pp. 833-840.

Khaliq, W. and Ehsan, M. B. (2016) 'Crack healing in concrete using various bio influenced selfhealing techniques', Construction and Building Materials, 102, pp. 349-357. doi: 10.1016/j.conbuildmat.2015.11.006.

Kim, H. K. et al. (2013) 'Microbially mediated calcium carbonate precipitation on normal and lightweight concrete', Construction and Building Materials, 38, pp. 1073-1082. doi: 10.1016/j.conbuildmat.2012.07.040.

De Koster, S. A. L. et al. (2015) 'Geopolymer coating of bacteria-containing granules for use in self-healing concrete', Procedia Engineering, 102, pp. 475-484. doi:

10.1016/j.proeng.2015.01.193.

Lucas, S. S. et al. (2018) 'Study of self-healing properties in concrete with bacteria encapsulated in expanded clay', Science and Technology of Materials, 30, pp. 93-98. doi: 10.1016/j.stmat.2018.11.006.

Luo, M., Qian, C. X. and Li, R. Y. (2015) 'Factors affecting crack repairing capacity of bacteriabased self-healing concrete', Construction and Building Materials, 87, pp. 1-7. doi: 10.1016/j.conbuildmat.2015.03.117.

Marvasi, M. et al. (2010) 'Physiological requirements for carbonateprecipitation during bio£lmdevelopmentof BacillussubtilisetfAmutant Massimiliano', Federation of European Microbiological Societies (FEMS) Microbiology Ecology, 71, pp. 341-350. doi: 10.1111/j.15746941.2009.00805.x.

Marvasi, M., Davila-Vazquez, Y. C. and Martinez, L. C. (2013) 'Laboratory Activity to Effectively Teach Introductory Geomicrobiology Concepts to Non-Geology Majors', Journal of Microbiology e Biology Education, 14(2), pp. 206-212. doi:

http://dx.doi.org/10.1128/jmbe.v14i2.578.

Monteiro., P. K. M. e P. J. M. (2014) Concreto: Microestrutura, Propriedades e Materiais. 2nd edn. São Paulo: IBRACON.

Nain, N. et al. (2019) 'Enhancement in strength parameters of concrete by application of Bacillus bacteria', Construction and Building Materials, 202, pp. 904-908. doi:

10.1016/j.conbuildmat.2019.01.059.

Nguyen, T. H. et al. (2019) 'Bacterial self-healing of concrete and durability assessment', Cement and Concrete Composites, 104, pp. 1-15. doi: 10.1016/j.cemconcomp.2019.103340.

Pacheco-Torgal, F. and Labrincha, J. A. (2013) 'Biotech cementitious materials: Some aspects of an innovative approach for concrete with enhanced durability', Construction and Building Materials, 40, pp. 1136-1141. doi: 10.1016/j.conbuildmat.2012.09.080. 
Pei, R. et al. (2013) 'Use of bacterial cell walls to improve the mechanical performance of concrete', Cement and Concrete Composites, 39, pp. 122-130. doi:

10.1016/j.cemconcomp.2013.03.024.

Ramachandran, S. K., Ramakrishnan, V. and Bang, S. S. (2001) 'Remediation of concrete using micro-organisms', ACI Materials Journal, 98(1), pp. 3-9. doi: 10.14359/10154.

Repette, W. L. (2011) 'Concretos para fins especiais e de última geração', in ISAIA, G. C. (ed.) Concreto: Ciência e Tecnologia. 1. São Paulo: IBRACON, p. 1968.

Schwantes-Cezario, N. et al. (2017) 'Bioprecipitation of calcium carbonate induced by Bacillus subtilis isolated in Brazil', International Biodeterioration and Biodegradation, 123, pp. 200-205. doi: 10.1016/j.ibiod.2017.06.021.

Schwantes-Cezario, N. et al. (2018) 'Crack filling in concrete by addition of bacillus subtilis spores - Preliminary study’, DYNA (Colombia), 85(205), pp. 132-139. doi:

10.15446/dyna.v85n205.68591.

Schwantes-Cezario, N., Nogueira, G. S. F. and Toralles, B. M. (2017) 'Biocimentação de compósitos cimentícios mediante adição de esporos de Bacillus subtilis AP91', Revista de Engenharia Civil IMED, 4(2), pp. 142-158. doi: https://doi.org/10.18256/2358-

6508.2017.v4i2.2072.

Van Tittelboom, K. et al. (2010) 'Use of bacteria to repair cracks in concrete', Cement and Concrete Research, 40(1), pp. 157-166. doi: 10.1016/j.cemconres.2009.08.025.

Vashisht, R. and Shukla, A. (2020) 'Potential application of bacteria to improve the self-healing and strength of concrete', Journal of Building Pathology and Rehabilitation, 5(10), pp. 1-13. doi: $10.1007 / \mathrm{s} 41024-020-0073-5$.

Vijay, K., Murmu, M. and Deo, S. V. (2017) 'Bacteria based self healing concrete - A review', Construction and Building Materials, 152, pp. 1008-1014. doi:

10.1016/j.conbuildmat.2017.07.040.

Wang, J. et al. (2012) 'Use of silica gel or polyurethane immobilized bacteria for self-healing concrete', Construction and Building Materials, 26(1), pp. 532-540. doi:

10.1016/j.conbuildmat.2011.06.054.

Wang, J. et al. (2018) 'A chitosan based pH-responsive hydrogel for encapsulation of bacteria for self-sealing concrete', Cement and Concrete Composites, 93, pp. 309-322. doi:

10.1016/j.cemconcomp.2018.08.007.

Wiktor, V. and Jonkers, H. M. (2011) 'Quantification of crack-healing in novel bacteria-based self-healing concrete', Cement and Concrete Composites, 33(7), pp. 763-770. doi:

10.1016/j.cemconcomp.2011.03.012.

$\mathrm{Xu}$, J. and Yao, W. (2014) 'Multiscale mechanical quantification of self-healing concrete incorporating non-ureolytic bacteria-based healing agent', Cement and Concrete Research, 64, pp. 1-10. doi: 10.1016/j.cemconres.2014.06.003. 